\title{
Outcomes Of One-Staged Procedures To Treat Aortic Coarctation Complicated By Cardiac Anomalies
}

\section{Hongyuan Lin}

Chinese Academy of Medical Sciences and Peking Union Medical College

\section{Yi Chang}

Chinese Academy of Medical Sciences and Peking Union Medical College

\section{Xiangyang Qian ( $\square$ linhongyuan@fuwai.com )}

Chinese Academy of Medical Sciences and Peking Union Medical College

\section{Cuntao Yu}

Chinese Academy of Medical Sciences and Peking Union Medical College

\section{Xiaogang Sun}

Chinese Academy of Medical Sciences and Peking Union Medical College

\section{Research Article}

Keywords: aortic coarctation, bilateral aortofemoral bypass, hybrid, complicated COA, one-staged

Posted Date: February 21st, 2022

DOI: https://doi.org/10.21203/rs.3.rs-1364577/v1

License: (c) (1) This work is licensed under a Creative Commons Attribution 4.0 International License. Read Full License 


\section{Abstract}

Objective: One-staged surgical treatment of aortic coarctation combined with cardiac anomalies is challenging. We aim to evaluate the feasibility of bilateral aortofemoral bypass technique in one-staged surgery treating coractation by comparing surgical outcomes with catheter intervention plus stent(hybrid).

Methods: Between January 2012 and December 2017, 50 patients underwent one-staged surgical procedures to treat coarctation and repair concomitant cardiac anomalies, like aortic root dilatation, cardiac valvular disease and so on. Among them, 30 patients underwent bilateral aortofemoral bypass and 20 patients underwent hybrid procedure to treat coarctation. We retrospectively analyzed the data of these patients and compared the early and late results.

Results: All the baseline clinical characteristics were comparable between groups except that the mean age of bypass group was $39.5 \pm 14.0$ years which was older than hybrid group ( $27.9 \pm 8.5$ years, $P=0.002)$. Technical success was achieved in all patients, with no hospital death or other severe complications. Immediately after surgery, in bypass and hybrid group, the mean upper-limb systolic blood pressure decreased from $159.4 \mathrm{mmHg}$ to $119.7 \mathrm{mmHg}$ and $148.4 \mathrm{mmHg}$ to $111.6 \mathrm{mmHg}$, the median peak systolic gradient decreased from $68.0 \mathrm{mmHg}$ to $10 \mathrm{mmHg}$ and $46.5 \mathrm{mmHg}$ to $10 \mathrm{mmHg}$ respectively $(P=0.09)$. And the mean upper-lower limbs gradient decreased from $21.7 \mathrm{mmHg}$ to $5.9 \mathrm{mmHg}$ and $21.0 \mathrm{mmHg}$ to $2.7 \mathrm{mmHg}$ respectively $(\mathrm{P}=0.104)$. The mean follow-up time was $76.92 \pm 18.7$ in bypass group and $85.4 \pm 20.6$ months in hybrid group. There were 4 late deaths in bypass group (one died of gastrointestinal bleeding, one died of pulmonary embolism and the other two died of heart failure caused by mechanical prosthetic valve dysfunction). The follow-up peak systolic gradient and other blood pressure parameters showed stable and no differences between two groups.

Conclusions: The bilateral aortofemoral bypass surgery is a safe and effective method which can be used in one-staged surgical strategy to treat coarctation complicated by cardiac anomalies and can be an alternative to the hybrid method.

\section{Introduction}

Aortic coarctation (COA) accounts for $5-7 \%$ of congenital heart disease.[1] In adults, COA is more likely to be associated with other cardiac anomalies,[2] for instance, bicuspid aortic valve, aortic regurgitation or stenosis and ventricular septal defect,[2] leading to a challenge for surgeons. The traditional approach is a staged procedure using both median sternotomy and left thoracotomy. However, there is a considerably increased risk when COA repair is performed ahead of severe concomitant cardiac anomalies.[3] Furthermore, damage to the recurrent laryngeal or phrenic nerves, bleeding in long-standing COA with extensive collateral vessels and aneurysms in the treated segment are main deficiencies of surgical correction. $[4,5]$ In recent years, in order to reduce the risk of staged procedures, one-stage repair for COA combined with other cardiac anomalies has been tried in an increasing number of cardiac centers.[6-8] 
The most common one-stage strategies for COA management include ascending to descending or abdominal aorta extra-anatomic bypass $[7,9]$ and hybrid balloon angioplasty with stent implantation.[8, $10,11]$ However, there are no reports of one-stage strategy using aortofemoral bypass (AFB), as another extra-anatomic manner, to treat such complicated COAs. Recently, the stenting technique has gradually replaced the traditional surgical correction of isolated COA in adult patients,[12] attributing to its avoidance of the acute complications caused by thoracotomy and its satisfactory outcomes.[12,13] In spite of that, acute aortic wall injury is often a dramatic event of the stenting technique, and may be more frequent in elderly patients with highly calcified tissue or hypoplastic vessels with reduced elasticity.[14] In contrast, extra-anatomic bypass could be feasible in all candidates irrespective of COA features. Theoretically, among extra-anatomic strategies, AFB is an easy and simple method with minimal trauma and lowest risk. The objective of this study is to evaluate the feasibility of AFB technique in one-staged surgery treating COA by comparing surgical outcomes with hybrid technique.

\section{Patients And Methods}

This study had been approved by institutional review board of Fuwai hospital, Peking union medical college and Chinese academy of medical sciences. All the consents of patients had been obtained.

Between January 2012 and December 2017, we enrolled consecutive COA patients who were concomitant with other cardiac anomalies underwent one-stage AFB surgery or one-stage hybrid surgery using femoral pathway. Patients eligible for AFB or stent implantation had native COA associated with hypertension (right upper limb's non-invasive blood pressure $>130 / 80 \mathrm{mmHg}$ ) and a resting non-invasive pressure gradient $>20 \mathrm{mmHg}$ between upper and lower limbs.[15] Excluded patients had one of the following: (1) age< 16 years; (2) contraindication to antiplatelet or anticoagulation therapy; (3) other etiology of secondary hypertension. All patients were preoperatively examined by echocardiography and aortic computed tomography angiography (CTA) to assess cardiac structural and functional abnormalities and severity of aortic coarctation. In this study, we exhibited the severity of coarctation using the ratio $(\%)$ of the narrowest COA dimension $(\mathrm{mm})$ to the dimension of the normal descending aorta at diaphragm level(mm).[16] The upper and lower limb blood pressures (BPs) for analysis were noninvasively measured in all patients. The upper limb BPs were measured in the right side.

Surgical technique

\section{AFB strategy}

The patient was placed in a supine position and invasive upper and lower limb BPs were monitored. First, bilateral femoral arteries were dissected through groin incisions (longitudinal or transverse). Second, repair procedure for the concomitant cardiac anomaly was conducted through median sternotomy. The arterial cannulation sites were selected as follow: femoral artery was cannulated for lower body perfusion and ascending aorta or right axillary artery (when ascending aorta should be replaced) was cannulated for upper body perfusion. After the concomitant cardiac procedure was completed, a Y-shaped prosthetic conduit (MAQUET, polytetrafluoroethylene, diameter $16-9 \mathrm{~mm}$ or $18-9 \mathrm{~mm}$ ) was delivered through the 
tunnel in peritoneal cavity from mediastinum toward the groin incision using a smooth-ended tunnelizer. The prosthetic conduit was first anastomosed to the ascending aorta by end-to-side after the ascending aorta was partially clamped. The conduit was then anastomosed to both femoral arteries. (Fig. 2)

2. Hybrid strategy

The position and monitor of BPs were the same as the AFB strategy. All the patients had the retrograde femoral artery catheterization. After advancing a flexible guidewire across the coarctation, a pigtail catheter was advanced over the wire into the aortic arch. In those with severe coarctation, graded dilatation by progressively larger balloons was performed. The balloon size for pre-dilation was adjusted based on the coarctation anatomy but not more than 5 times the stenosis diameter. The stent diameter was selected to be $20-30 \%$ greater than the diameter of the normal aorta at the level of distal arch. The stent length was selected to ensure that the stenosed segment was in the middle of the stent. After deployment of the stent, post-dilation was performed with a balloon in some patients with a pressure gradient of more than $5 \mathrm{mmHg}$. The maximum diameter of the balloon was selected not more than the diameter of the descending thoracic aorta at the level of the diaphragm. Finally, angiography was repeated and the pressure was recorded across the stented segment. The cardiac procedure was then performed through median sternotomy. Detailed information of all stents and balloons used was showed in supplement Table 1. 
Table 1

Main clinical characteristics of patients

\begin{tabular}{|c|c|c|c|c|}
\hline Variables & $\begin{array}{l}\text { Overall } \\
(n=50)\end{array}$ & $\begin{array}{l}\text { Surgical } \\
\text { group }(n= \\
\text { 30) }\end{array}$ & $\begin{array}{l}\text { Hybrid } \\
\text { group }(n=\end{array}$ & $P$ value \\
\hline Female, N (\%) & $16(32.0)$ & $9(30.0)$ & $7(35.0)$ & 0.951 \\
\hline Age (years), mean \pm SD & $\begin{array}{l}34.9 \pm \\
13.3\end{array}$ & $39.5 \pm 14.0$ & $27.9 \pm 8.5$ & $0.002^{\star \star}$ \\
\hline $\mathrm{BSA}\left(\mathrm{m}^{2}\right)$, mean $\pm \mathrm{SD}$ & $1.8 \pm 0.2$ & $1.8 \pm 0.2$ & $1.7 \pm 0.2$ & 0.348 \\
\hline $\mathrm{BMI}\left(\mathrm{kg} / \mathrm{m}^{2}\right)$, mean $\pm \mathrm{SD}$ & $21.7 \pm 3.8$ & $22.5 \pm 3.8$ & $20.5 \pm 3.7$ & 0.062 \\
\hline Previous stroke, $\mathrm{N}(\%)$ & $3(6.0)$ & $3(10.0)$ & $0(0.0)$ & 0.395 \\
\hline Tobacco use, N (\%) & $13(26.0)$ & $8(26.7)$ & $5(25.0)$ & 1 \\
\hline LVEF (\%), median [IQR] & $\begin{array}{l}63.0[59.3, \\
67.8]\end{array}$ & $\begin{array}{l}\text { 61.5[58.0, } \\
67.0]\end{array}$ & $\begin{array}{l}65.0[62.5, \\
68.3]\end{array}$ & 0.187 \\
\hline $\begin{array}{l}\text { Baseline upper-limb systolic blood pressure } \\
(\mathrm{mmHg}) \text {, mean } \pm \text { SD }\end{array}$ & $\begin{array}{l}155 \pm \\
27.2\end{array}$ & $159.4 \pm 28.1$ & $148.4 \pm 24.2$ & 0.153 \\
\hline PSG baseline(mmHg), median [IQR] & $\begin{array}{l}58.5[40.0, \\
75.5]\end{array}$ & $\begin{array}{l}68.0[41.5, \\
78.6]\end{array}$ & $\begin{array}{l}46.5[36.8, \\
67.0]\end{array}$ & 0.073 \\
\hline $\begin{array}{l}\text { Mean upper-lower limb blood gradient } \\
\text { pressure }(\mathrm{mmHg}), \text { mean } \pm \text { SD }\end{array}$ & $21.4 \pm 7.9$ & $21.7 \pm 8.2$ & $21.0 \pm 7.8$ & 0.744 \\
\hline $\mathrm{ABI}$, mean $\pm \mathrm{SD}$ & $\begin{array}{l}0.63 \pm \\
0.12\end{array}$ & $0.60 \pm 0.13$ & $0.66 \pm 0.1$ & 0.066 \\
\hline $\begin{array}{l}\text { Diameter of narrowest aorta/Diameter of } \\
\text { normal aorta(\%), median [IQR] }\end{array}$ & $16[9,27]$ & $15[6,20]$ & $22[12,33]$ & $0.038^{\star}$ \\
\hline $\begin{array}{l}\text { Diameter of narrowest aorta(mm), median } \\
\text { [IQR] }\end{array}$ & $\begin{array}{l}4.0[2.4 \\
7.9]\end{array}$ & $4.0[2.0,7.6]$ & $4.5[3.0,9.1]$ & 0.218 \\
\hline $\begin{array}{l}\text { Coarctation measurement, mm/BSA, } \\
\text { median [IQR] }\end{array}$ & $\begin{array}{l}2.5[1.3 \\
4.5]\end{array}$ & $2.4[1.1,4.2]$ & $2.8[1.6,5.1]$ & 0.177 \\
\hline \multicolumn{5}{|c|}{$\begin{array}{l}\text { BSA: body surface area, BMI: body mass index, CPB: cardio-pulmonary bypass, PSG baseline: } \\
\text { baseline peak systolic gradient, IQR: interquartile range, SD: standard deviation, ABI: ankle brachial } \\
\text { index }\end{array}$} \\
\hline
\end{tabular}

Follow up

Patients were followed up with a mailed questionnaire or telephone call, by contacting the referring cardiologist or general practitioner. We defined PSG $>20 \mathrm{mmHg}$ and(or) imaging (CTA or ultrasound) findings of significant stenosis (or occlusion) in the stent or artificial graft as the positive event, considering that PSG $>20 \mathrm{mmHg}$ is a recognized interventional indication of COA.[17] 
Categorical variables were reported as frequency (percentage\%), and were compared between groups with the chi-squared test. Shapiro-wilk test was adopted for normal distribution analysis. Continuous variables were reported as mean \pm SD or as median with interquartile range(as median[IQR]), and were compared with the two-sample $t$ test (paired $t$ test for the normal distribution data collected at different time points from the same group) or the Wilcoxon rank sum test as appropriate. $P$ value of less than 0.05 was considered statistically significant. R software version 4.0.2 was used for statistical analysis. Graphpad Prism for Windows version 6.0 was used to create graphs.

\section{Results}

50 patients were enrolled in this study, and were separated into AFB group $(n=30)$ or hybrid group $(n=$ 20). All the cases were technical success. The baseline clinical data was listed in Table 1. The mean age of the AFB group was $39.5 \pm 14.0$ years, older than the hybrid group $(27.9 \pm 8.5$ years, $P=0.002)$. The median diameter of the narrowest COA segment was $4.0 \mathrm{~mm}$ for the AFB group and $4.5 \mathrm{~mm}$ for the hybrid group $(P=0.218)$. The ratio of the narrowest $C O A$ dimension $(\mathrm{mm})$ to the dimension of the normal descending aorta at diaphragm level $(\mathrm{mm})$ in the AFB group was 0.15 , whereas the ratio was 0.22 in the hybrid group $(P=0.038)$. The mean right upper limb systolic blood pressure (SBP) of the whole cohort was $155 \pm 27.2 \mathrm{mmHg}, 159.4 \pm 28.1 \mathrm{mmHg}$ for the AFB group and $148.4 \pm 24.2 \mathrm{mmHg}$ for the hybrid group, respectively $(P=0.153)$. The median peak systolic gradient $(P S G)$ which was defined as upper limb SBP minus lower limb SBP, was $58.5 \mathrm{mmHg}$ in total, and $68.0 \mathrm{mmHg}$ for the AFB group and $46.5 \mathrm{mmHg}$ for the hybrid group $(P=0.073)$. The mean upper-lower limbs blood gradient pressure was $21.4 \pm 7.9 \mathrm{mmHg}$ in total, $21.7 \pm 8.2 \mathrm{mmHg}$ for the AFB group and $21.0 \pm 7.8 \mathrm{mmHg}$ for the hybrid group $(P=0.744)$. The concomitant cardiac surgical procedures were summarized in Table 2. 
Table 2

Concomitant cardiac surgery

\begin{tabular}{|llll|}
\hline Concomitant cardiac surgery & Surgical $(\mathbf{n = 3 0})$ & Hybrid $(\mathbf{n = 2 0})$ & Total $(\mathbf{n}=\mathbf{5 0})$ \\
\hline Bentall + MVR & 3 & 1 & 4 \\
\hline Bentall & 8 & 3 & 11 \\
\hline Bentall + TAR & 1 & 1 & 2 \\
\hline Wheat's & 1 & 1 & 2 \\
\hline CABG & 3 & 0 & 3 \\
\hline AVR & 7 & 7 & 14 \\
\hline MVR & 0 & 1 & 1 \\
\hline MVR + AVR & 1 & 0 & 1 \\
\hline MVP & 0 & 3 & 3 \\
\hline VSD repair & 3 & 3 & 6 \\
\hline Others & 3 & 0 & 3 \\
\hline MVR: mitral valve replacement; TAR: total arch replacement; CABG: coronary artery bypass grafting; \\
AVR: aortic valve replacement; MVP: mitral valve plasty; VSD: ventricular septal defect.
\end{tabular}

The immediate operative outcomes were listed in Table 3. No perioperative death or severe complications were observed before discharge. There was no difference between groups in terms of the degree of SBP decline $(P=0.095$, paired T-test). In addition, the PSG, mean upper-lower limbs blood pressure gradient and ankle brachial index $(\mathrm{ABI})$ were apparently improved without differences $(P>0.05$, paired T-test) between groups. (Figure.1) With respect to ICU stay and postoperative hospital stay, there were no differences between groups. (Table 3) 
Table 3

Perioperative outcomes of patients

\begin{tabular}{|c|c|c|c|c|}
\hline Variables & $\begin{array}{l}\text { Overall }(n \\
=50)\end{array}$ & $\begin{array}{l}\text { Surgical } \\
\text { group }(n= \\
30)\end{array}$ & $\begin{array}{l}\text { Hybrid } \\
\text { group }(n= \\
20)\end{array}$ & $P$ value \\
\hline CPB time (minutes), mean \pm SD & $\begin{array}{l}96.9 \pm \\
47.8\end{array}$ & $105.8 \pm 49.6$ & $83.7 \pm 42.9$ & 0.108 \\
\hline ventilation time (hours), median [IQR] & $\begin{array}{l}15.5 \\
{[13.0} \\
18.0]\end{array}$ & $\begin{array}{l}\text { 17.0[13.3, } \\
20.0]\end{array}$ & $\begin{array}{l}14.5[12.8 \\
17.0]\end{array}$ & 0.121 \\
\hline Drainage $(\mathrm{ml})$, median [IQR] & $\begin{array}{l}1,030 \\
{[726,} \\
1836]\end{array}$ & $\begin{array}{l}1560[970, \\
2220]\end{array}$ & $\begin{array}{l}727[577 \\
1020]\end{array}$ & $<.001 * \star \star$ \\
\hline Drains in situ (days), median [IQR] & $5[4,6]$ & $6[4,8.75]$ & $4[3.75,5]$ & $0.01 *$ \\
\hline $\begin{array}{l}\text { Upper-limb systolic blood pressure } \\
\text { (mmHg), mean } \pm \text { SD }\end{array}$ & $\begin{array}{l}116.4 \pm \\
12.2\end{array}$ & $119.7 \pm 11.5$ & $111.6 \pm 11.5$ & $0.022^{*}$ \\
\hline PSG post (mmHg), median [IQR] & $\begin{array}{l}10.0[3.0 \\
14.0]\end{array}$ & $\begin{array}{l}10.0[4.0, \\
16.25]\end{array}$ & $\begin{array}{l}10.0[2.25 \\
13.25]\end{array}$ & 0.555 \\
\hline$\triangle \mathrm{PSG}(\mathrm{mmHg}) \dagger$, median $[\mathrm{IQR}]$ & $\begin{array}{l}48.0 \\
{[27.0} \\
65.5]\end{array}$ & $\begin{array}{l}52.5[37.0 \\
65.5]\end{array}$ & $\begin{array}{l}32.5[24.5 \\
61.5]\end{array}$ & 0.09 \\
\hline $\begin{array}{l}\text { Mean upper-lower limb blood gradient } \\
\text { pressure (mmHg), median [IQR] }\end{array}$ & $\begin{array}{l}5.0[1.25 \\
7.22]\end{array}$ & $5.9[4.1,8.8]$ & $2.7[0.2,6.7]$ & 0.104 \\
\hline$A B I$ & $\begin{array}{l}0.92 \pm \\
0.10\end{array}$ & $0.92 \pm 0.11$ & $0.93 \pm 0.1$ & 0.666 \\
\hline ICU days, mean \pm SD & $2 \pm 1.3$ & $2 \pm 1.3$ & $2 \pm 1.2$ & 0.939 \\
\hline $\begin{array}{l}\text { postoperative hospital stay (days), mean } \pm \\
\text { SD }\end{array}$ & $9.0 \pm 3.6$ & $9.5 \pm 4.1$ & $8.1 \pm 2.0$ & 0.16 \\
\hline \multicolumn{5}{|c|}{$\begin{array}{l}\text { IQR: interquartile range, SD: standard deviation, PSG post: postoperative peak systolic gradient, ABI: } \\
\text { ankle brachial index, ICU: intensive care unit. }\end{array}$} \\
\hline
\end{tabular}

The follow-up outcomes were listed in Table 4. The mean follow-up time was $80.17 \pm 19.6$ months (48112 months). There were 4 late deaths which were excluded from the analysis of the follow-up data. All these 4 late deaths were in the AFB group, but were not related to graft, COA or COA-related complications (for examples, cerebral hemorrhage caused by hypertension). One died of gastrointestinal bleeding 1 year after surgery, one died of pulmonary embolism 6 years after surgery and the other two died of heart failure caused by mechanical valve dysfunction 3 and 6 years after surgery. All the survivors $(n=46)$ had no COA related symptoms (lower limb ischemia or hypertension related symptoms). There were 2 cases in the AFB group developing unilateral graft occlusion during the follow-up. However, the BPs of the 
affected lower limbs remained intact compared to the contralateral limbs, which was considered related to sufficient blood flow provided from the contralateral side. No graft infection was found throughout the follow-up despite that the graft conduits were intraperitoneal. The mean upper limb SBP was $130.8 \pm$ $13.6 \mathrm{mmHg}, 132.8 \pm 12.1 \mathrm{mmHg}$ for the AFB group and $127.6 \pm 15.3 \mathrm{mmHg}$ for the hybrid group $(P=$ $0.264)$. The mean PSG was $13.4 \pm 9.2 \mathrm{mmHg}$ in total, $13.7 \pm 8.9 \mathrm{mmHg}$ for the AFB group and $12.9 \pm$ $9.7 \mathrm{mmHg}$ for the hybrid group $(P=0.776)$. The median upper-lower limbs blood gradient pressure was $8.2 \mathrm{mmHg}$ in total, $9.2 \mathrm{mmHg}$ for the AFB group and $8.0 \mathrm{mmHg}$ for the hybrid group $(P=0.947)$.

Table 4

Follow-up outcomes of patients

\begin{tabular}{|c|c|c|c|c|}
\hline Variables & $\begin{array}{l}\text { Overall } \\
(n=46)\end{array}$ & $\begin{array}{l}\text { Surgical } \\
\text { group }(n= \\
26)\end{array}$ & $\begin{array}{l}\text { Hybrid } \\
\text { group }(n= \\
20)\end{array}$ & $\begin{array}{l}P \\
\text { value }\end{array}$ \\
\hline Follow-up time(months), mean \pm SD & $\begin{array}{l}80.17 \pm \\
19.6\end{array}$ & $76.92 \pm 18.7$ & $85.4 \pm 20.6$ & 0.176 \\
\hline Regular CTA, N (\%) & $17(37.0)$ & $11(42.3)$ & $6(30.0)$ & 0.785 \\
\hline $\begin{array}{l}\text { PSG }>20 \mathrm{mmHg} \text { or severe stenosis of the graft } \\
\text { revealed by CTA or ultrasound, } \mathrm{N}(\%)\end{array}$ & 9 (19.6) & $5(19.2)$ & $4(20.0)$ & 1 \\
\hline $\begin{array}{l}\text { Upper-limb systolic blood pressure (mmHg), } \\
\text { mean } \pm S D\end{array}$ & $\begin{array}{l}130.8 \pm \\
13.6\end{array}$ & $132.8 \pm 12.1$ & $\begin{array}{l}127.6 \pm \\
15.3\end{array}$ & 0.264 \\
\hline PSG FU(mmHg), mean \pm SD & $\begin{array}{l}13.4 \pm \\
9.2\end{array}$ & $13.7 \pm 8.9$ & $12.9 \pm 9.7$ & 0.776 \\
\hline$\triangle \mathrm{PSG}(\mathrm{mmHg}) \dagger$, median [IQR] & $\begin{array}{l}46.0 \\
{[24.3,} \\
61.8]\end{array}$ & $\begin{array}{l}51.5[27.0, \\
63.8]\end{array}$ & $\begin{array}{l}36.5[23.0 \\
52.0]\end{array}$ & 0.150 \\
\hline $\begin{array}{l}\text { Mean upper-lower limb blood gradient pressure } \\
(\mathrm{mmHg}), \text { median [IQR] }\end{array}$ & $\begin{array}{l}8.2[4.6 \\
14.0]\end{array}$ & $\begin{array}{l}9.2[5.18 \\
13.2]\end{array}$ & $\begin{array}{l}8.0[2.3 \\
14.3]\end{array}$ & 0.947 \\
\hline $\mathrm{ABI}$, mean $\pm \mathrm{SD}$ & $0.9 \pm$ & $0.9 \pm 0.08$ & $0.91 \pm 0.09$ & 0.676 \\
\hline \multicolumn{5}{|c|}{$\begin{array}{l}\text { IQR: interquartile range, SD: standard deviation, PSG FU: follow-up peak systolic gradient, CTA: } \\
\text { computed tomographic angiography, ABI: ankle brachial index }\end{array}$} \\
\hline \multicolumn{5}{|l|}{ † $\triangle \mathrm{PSG}=$ (baseline $\mathrm{PSG}$ )-(last follow-up PSG) } \\
\hline
\end{tabular}

Blood pressure relevant parameters were displayed in Fig. 1. The improvement was pronounced in both groups and no difference was presented between groups.

\section{Discussion}

COA concomitant with other cardiac anomalies requiring surgical intervention is associated with greater risk for correction, especially in adults. For a long time, a staged surgical strategy was proposed for these patients. The conventional staged strategy usually includes an anatomic correction of COA through 
thoracotomy and a cardiac surgery through sternotomy. The separated operations have some notable disadvantages: (1) The first-stage COA repair might produce fatal hemodynamic instability if the concomitant cardiac lesion is severe enough. $[7,9](2)$ The traditional COA anatomical correction is prone to damage the recurrent laryngeal nerve and might suffer a terrible bleeding problem when the coarctation is long-standing with rich collateral circulation.[5] (3) Patients need to undergo two different incisions which lead to a greater trauma and heavier cost. Concerning the cumulative risks of staged strategy, one-stage strategy has been more popular in recent years. One-stage strategy for COA management usually involves one of the following techniques: extra-anatomic bypass from ascending aorta to abdominal aorta; intrapericardial ascending-descending aortic bypass and balloon plasty with stent implantation (hybrid surgery). Moreover, in current study, we innovatively adopted aortofemoral bypass (AFB) technique to deal with COA in one-stage strategy. Even though the ascending to descending or abdominal aorta bypass has become a standard manner in one-stage strategy and has been proved effective by some other studies[7, 9, 18], the AFB technique, also known as a manner of extra-anatomic bypass, outperform the traditional extra-anatomic techniques in following aspects: (1) simple procedure: the distal anastomosis sites are at bilateral femoral arteries which are much easier to be exposed and dissected. (2) relatively less or small incisions: no lateral thoracotomy or laparotomy is required. (3) less abdominal complications: the AFB technique, unlike the traditional manner which may disturb abdominal organs when performing the distal anastomosis, seldom affects the abdominal organs. (4) lower risk of distal anastomosis bleeding and easier hemostasis: the distal anastomoses of AFB have less probabilities to bleed due to lower tension. Even if there is bleeding, it is easy to be found and ended. On the contrary, the traditional manner could not provide a good access to the bleeding anastomosis. However, the main problem of AFB is the long-term patency of the graft vessels. JD Crawford et al[19] reported a 3-year graft patency of $80 \%$ in aortoiliac occlusive patients treated with thoracofemoral bypass. In current study, occlusion occurred only in 2 cases (7.7\%) during the follow-up. The long-term patency was promising.

The intrapericardial ascending-descending aortic bypass is an extra-anatomic approach that uses a shorter graft probably less prone to occlusions. However, in such method, the heart is retracted cephalad, which will affect hemodynamics and require the assistance of CPB, especially for those who need synchronous cardiac surgery. Furthermore, the exposure is especially difficult in obese patients or those with barrel-shaped thorax.[9]

Anatomic correction with an interposition graft implanted via the median sternotomy is the optimal method for junior COA patients without previous interventions, even for those complicated with cardiac defects. However, in some adult COA patients, the lesions are often more troublesome: the vascular elasticity is reduced, and the collateral circulation is extremely rich. It is difficult to perform COA anatomical correction with synchronous cardiac surgery through midline incision. Consequently, a concomitant extra-anatomic bypass for COA may have a better prognosis. This study is the first to preliminarily assess the feasibility of AFB method for one-stage treatment of complicated COA. Due to the lack of experience and the very limited number of cases, no clear indications for AFB could be established. 
Over the decades, the interventional stenting technology has achieved very fruitful clinical results in treatment of $\operatorname{COA},[12,14,20,21]$ and has become the treatment of first choice in adults in many centers. [22] However, the stents are not suitable for the coarctation located at the arch of which the curvature is too sharp. The reason could be an increased incidence of internal leakage outgrowth of the poor morphological structure match between stents and highly curved arch vessels.[10, 17, 23] Besides, in severe stenosis or arch hypoplasia cases, the stenting method is related to a poorer prognosis with a higher re-intervention rate.[12] Forbes et al[16] reported a multicenter study with a large sample size ( $\mathrm{n}=$ 217) on stenting for $\mathrm{COA}$, suggesting that patients with restenosis after stenting and requiring reintervention or surgery had an average baseline stenosis degree (ratio of coarctation dimension to the normal aortic dimension at diaphragm level) of $25 \%$ and an average postoperative stenosis degree of $66 \%$, which was much lower than the mean postoperative degree $(82 \%)$ of the whole group. He suggested that postoperative ratio of $60 \%$ appeared to be an important ratio regarding the requirement for reintervention.[16] Therefore, a patient with more severe stenosis would have a higher probability of reintervention after stenting. Similarly, we also found that in our study, the severity of stenosis was greater in the AFB group than the hybrid group ( $15 \%$ vs $22 \%, p=0.038$, see Table 1 ). Consequently, it is reasonable to consider AFB if the ratio is low. Furthermore, Forbes et al[24] revealed a higher aortic wall injury rate in hypoplasia cases when treated with stenting. In summary, we suggested that the elder and hypoplasia patients should tend to the extra-anatomic strategy due to the calcification and reduced elasticity of the aortic wall tissue.

Compared with AFB strategy, the one-stage hybrid procedure has higher requirement on skills and facilities, needing a hybrid operation room and a hybrid team. Consequently, it is not easy to carry out in smaller cardiac centers. Otherwise, the hospitalization time and cost will be significantly increased if adopting a two-stage hybrid strategy instead.

Both of the AFB and hybrid strategy could significantly improve the BP relevant parameters (PSG, mean upper-lower limbs blood gradient pressure, upper limb SBP and ABI) after surgery (Fig. 1). No differences were found between groups, suggesting that the AFB technique had the similar effect on systemic BP compared with the hybrid (stenting) technique. Although 2 cases of unilateral graft occlusion were identified in AFB group during the follow-up, their homolateral lower limbs' BPs were intact and no reintervention indications were ascertained, proving that the contralateral bridge graft could provide sufficient blood flow to the occluded side.

The positive event (PSG $>20 \mathrm{mmHg}$ or imaging findings of significant stenosis or occlusion in the stent or artificial graft) rates of two groups were almost the same ( $19.2 \%$ vs $20.0 \%, p=1.0$, Table 4$)$. The hybrid strategy is undoubtedly irreplaceable, but pending further studies, it is reasonable to select the AFB strategy as an alternative in light of its promising outcomes.

\section{Limitations}

In this study, follow-up results showed that the proportion of patients undergoing regular aortic CTA beyond one year after surgery was not high. A total of $17 / 46$ patients in the whole group underwent aortic 
CTA one year after surgery, the AFB group had $11 / 26$ patients and the hybrid group had $6 / 20$ patients. The possible reason is that patients in our center came from across the whole country, but follow-up examinations were often conducted locally, the regional differences in medical resources and knowledge level led to an ignorance of routine aortic CTA exams in most inexperienced medical institutions.

Future work

In this study, 2 cases in the AFB group had graft-related occlusion. Unfortunately, there is no guideline or consensus on anticoagulation methods for the artificial graft. Researches could be carried out on the anticoagulation strategy of AFB to better the management of such patients.

\section{Conclusion}

The bilateral aortofemoral bypass surgery is a safe and effective method which can be used in onestaged surgical strategy to treat coarctation complicated by cardiac anomalies and can be an alternative to the hybrid method.

\section{Abbreviations}

COA: coarctation; AFB: aortofemoral bypass; CTA: computed tomography angiography; BP: blood pressure; SBP: systolic blood pressure; PSG: peak systolic gradient; ABI: ankle brachial index; ICU: intensive care unit.

\section{Declarations}

Ethics approval and consent to participate

This study had been approved by institutional review board of Fuwai hospital, Peking union medical college and Chinese academy of medical sciences. All methods were performed in accordance with the relevant guidelines and regulations. The written informed consent was obtained from all participants. The permission to access and use the raw data was granted by Prof. Xiangyang Qian.

Consent for publication

Not applicable.

Availability of data and materials

The datasets used and/or analysed during the current study are available from the corresponding author on reasonable request.

Competing interests 
The authors declare that they have no competing interests.

Funding

None.

Authors' contributions

LHY analyzed the data and was a major contributor in writing the manuscript. CY collected the data and was in charge of the study design and manuscript modification. QXY, SXG and YCT was in charge of the administrative support. All authors read and approved the final manuscript.

Acknowledgments

We thank colleagues of the cardiovascular center of Fuwai hospital for support of our research.

Conflict of Interest: none declared

\section{References}

1. Bosse C, Ramadan R, Fabre D, Guihaire J. Cardiac surgery combined with bypass from the ascending aorta to the bilateral femoral arteries for severe aorto-iliac occlusion: A case series. J Thorac Cardiovasc Surg. 2018;155(4):1574-7.

2. Abjigitova $D$, Mokhles $M$, Witsenburg $M$, van de Woestijne $P$, Bekkers J, Bogers $A$. Surgical repair of aortic coarctation in adults: half a century of a single centre clinical experience. European journal of cardio-thoracic surgery : official journal of the European Association for Cardio-thoracic Surgery. 2019;56(6):1178-85.

3. Yin K, Zhang Z, Lin Y, Guo C, Sun Y, Tian Z, Xie Q, Wang C. Surgical management of aortic coarctation in adolescents and adults. Interactive cardiovascular and thoracic surgery. 2017;24(3):430-5.

4. Fisher M, Jonas S, Sacco RL, S J. Prophylactic neuroprotection for cerebral ischemia [published erratum appears in Stroke 1994 Jun;25(6):1300]. Stroke. 1994;25(5):1075-80.

5. Pennington DG, Liberthson RR, Jacobs M, Scully H, Daggett WM. Critical review of experience with surgical repair of coarctation of the aorta. Journal of Thoracic \& Cardiovascular Surgery. 1979;77(2):21729.

6. Li Q, Lin K, Gan C, Feng Y. One-Stage Hybrid Procedure to Treat Aortic Coarctation Complicated by Intracardiac Anomalies in Two Adults. The Annals of thoracic surgery. 2015;100(6):2364-7.

7. Ge YP, Li CN, Cheng LJ, Zheng T, Zheng J, Liu YM, Zhu JM, Sun LZ. One-Stage Repair of Adult Aortic Coarctation and Concomitant Cardiac Diseases: Ascending to Abdominal Aorta Extra-Anatomical Bypass Combined with Cardiac Surgery. Heart Lung Circ. 2019;28(11):1740-6. 
8. Russell T, Quarto C, Nienaber C. A single-stage hybrid approach for the management of severely stenotic bicuspid aortic valve, ascending aortic aneurysm, and coarctation of the aorta with a literature review. Journal of cardiology cases. 2018;17(6):183-6.

9. Wang R, Sun LZ, Hu XP, Ma WG, Chang Q, Zhu JM, Liu YM, Yu CT. Treatment of complex coarctation and coarctation with cardiac lesions using extra-anatomic aortic bypass. J Vasc Surg. 2010;51(5):1203-8.

10. Roselli E, Soltesz E, Mastracci T, Svensson L, Lytle B. Antegrade delivery of stent grafts to treat complex thoracic aortic disease. The Annals of thoracic surgery. 2010;90(2):539-46.

11. Ugur M, Alp I, Arslan G, Temizkan V, Ucak A, Yilmaz A. Four different strategies for repair of aortic coarctation accompanied by cardiac lesions. Interactive cardiovascular and thoracic surgery. 2013;17(3):467-71.

12. Meijs TA, Warmerdam EG, Slieker MG, Krings GJ, Molenschot MMC, Meijboom FJ, Sieswerda GT, Doevendans PA, Bouma BJ, de Winter RJ, Mulder BJM, Voskuil M. Medium-term systemic blood pressure after stenting of aortic coarctation: a systematic review and meta-analysis. Heart. 2019;105(19):1464-70.

13. Nguyen L, Cook SC. Coarctation of the Aorta: Strategies for Improving Outcomes. Cardiol Clin. 2015;33(4):521-30, vii.

14. Haji Zeinali AM, Sadeghian M, Qureshi SA, Ghazi P. Midterm to long-term safety and efficacy of selfexpandable nitinol stent implantation for coarctation of aorta in adults. Catheter Cardiovasc Interv. 2017;90(3):425-31.

15. Warnes C, Williams R, Bashore T, Child J, Connolly H, Dearani J, Del Nido P, Fasules J, Graham T, Hijazi Z, Hunt S, King M, Landzberg M, Miner P, Radford M, Walsh E, Webb G. ACC/AHA 2008 Guidelines for the Management of Adults with Congenital Heart Disease: Executive Summary: a report of the American College of Cardiology/American Heart Association Task Force on Practice Guidelines (writing committee to develop guidelines for the management of adults with congenital heart disease). Circulation. 2008;118(23):2395-451.

16. Forbes T, Kim D, Du W, Turner D, Holzer R, Amin Z, Hijazi Z, Ghasemi A, Rome J, Nykanen D, Zahn E, Cowley C, Hoyer M, Waight D, Gruenstein D, Javois A, Foerster S, Kreutzer J, Sullivan N, Khan A, Owada C, Hagler D, Lim S, Canter J, Zellers T. Comparison of surgical, stent, and balloon angioplasty treatment of native coarctation of the aorta: an observational study by the CCISC (Congenital Cardiovascular Interventional Study Consortium). Journal of the American College of Cardiology. 2011;58(25):2664-74.

17. Meadows J, Minahan M, McElhinney DB, McEnaney K, Ringel R. Intermediate Outcomes in the Prospective, Multicenter Coarctation of the Aorta Stent Trial (COAST). Circulation. 2015;131(19):1656-64.

18. Connolly H, Schaff H, Izhar U, Dearani J, Warnes C, Orszulak T. Posterior pericardial ascending-todescending aortic bypass: an alternative surgical approach for complex coarctation of the aorta. 
Circulation. 2001;104:1133-7.

19. Crawford JD, Scali ST, Giles KA, Back MR, Fatima J, Arnaoutakis DK, Berceli SA, Upchurch GJ, Huber TS. Contemporary outcomes of thoracofemoral bypass. J Vasc Surg. 2019;69(4):1150-9.e1.

20. van der Burg JJ, Warmerdam EG, Krings GJ, Meijboom FJ, van Dijk AP, Post MC, Veen G, Voskuil M, Sieswerda GT. Effect of stent implantation on blood pressure control in adults with coarctation of the aorta. Cardiovasc Revasc Med. 2018;19(8):944-50.

21. Hatoum I, Haddad R, Saliba Z, Abdel Massih T. Endovascular stent implantation for aortic coarctation: parameters affecting clinical outcomes. American journal of cardiovascular disease. 2020;10(5):528-37.

22. Erbel R, Aboyans V, Boileau C, Bossone E, Bartolomeo RD, Eggebrecht $H$, Evangelista A, Falk V, Frank H, Gaemperli O, Grabenwöger M, Haverich A, lung B, Manolis AJ, Meijboom F, Nienaber CA, Roffi M, Rousseau H, Sechtem U, Sirnes PA, Allmen RS, Vrints CJ. 2014 ESC Guidelines on the diagnosis and treatment of aortic diseases: Document covering acute and chronic aortic diseases of the thoracic and abdominal aorta of the adult. The Task Force for the Diagnosis and Treatment of Aortic Diseases of the European Society of Cardiology (ESC). Eur Heart J. 2014;35(41):2873-926.

23. Taggart NW, Minahan M, Cabalka AK, Cetta F, Usmani K, Ringel RE. Immediate Outcomes of Covered Stent Placement for Treatment or Prevention of Aortic Wall Injury Associated With Coarctation of the Aorta (COAST II). JACC Cardiovasc Interv. 2016;9(5):484-93.

24. Forbes TJ, Garekar S, Amin Z, Zahn EM, Nykanen D, Moore P, Qureshi SA, Cheatham JP, Ebeid MR, Hijazi ZM, Sandhu S, Hagler DJ, Sievert H, Fagan TE, Ringewald J, Du W, Tang L, Wax DF, Rhodes J, Johnston TA, Jones TK, Turner DR, Pedra CA, Hellenbrand WE. Procedural results and acute complications in stenting native and recurrent coarctation of the aorta in patients over 4 years of age: a multi-institutional study. Catheter Cardiovasc Interv. 2007;70(2):276-85.

\section{Figures}

\section{Figure 1}

Comparison of blood pressure related parameters between groups 


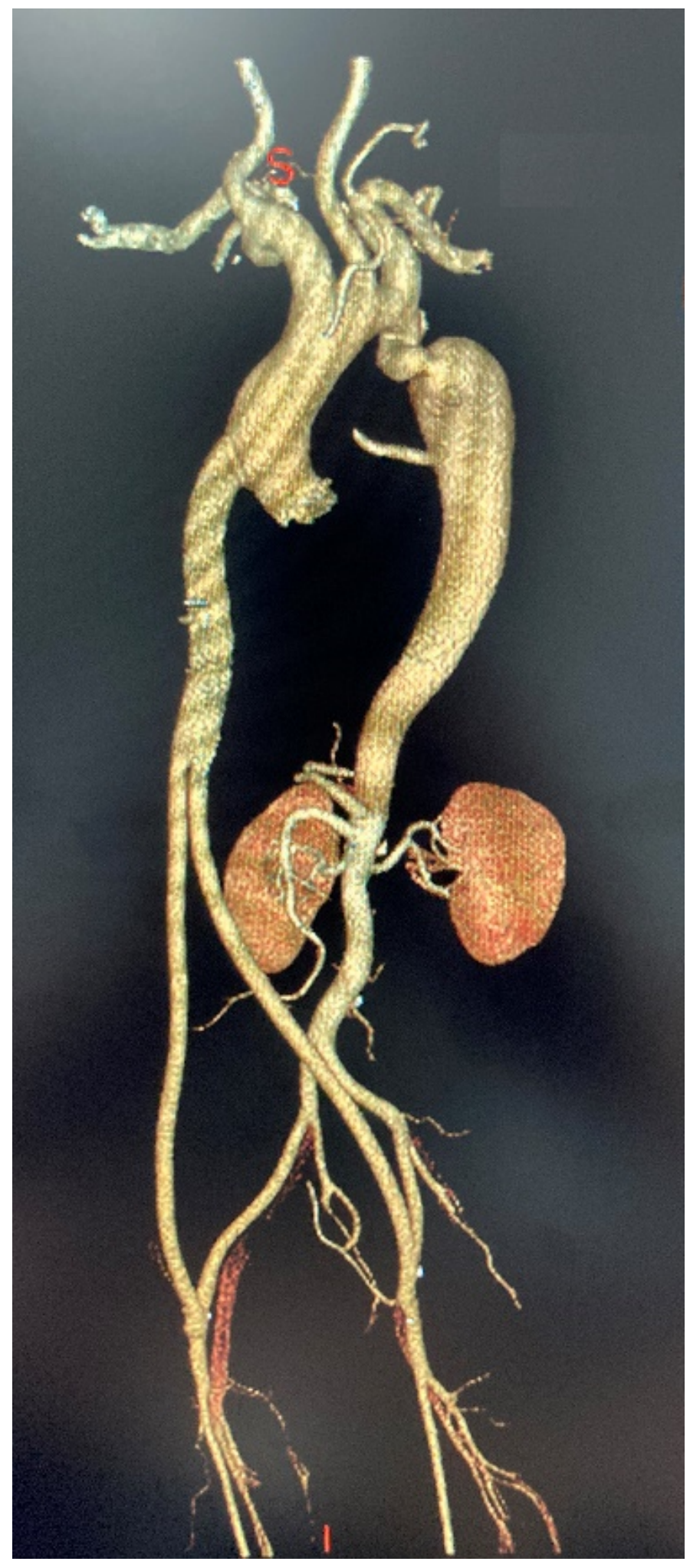

Figure 2

Postoperative CTA of AFB

\section{Supplementary Files}

This is a list of supplementary files associated with this preprint. Click to download. 
- Supplementtable1.docx 